\title{
An Analysis on the Factors Affecting Second Language Acquisition and Its Implications for Teaching and Learning*
}

\author{
Yuefang Sun \\ School of Foreign Languages, Jining Medical University, Jining, Shandong Province, China
}

\begin{abstract}
Affected by the overwhelming impact of globalization, many people have realized the importance of mastering a second language and begun to learn it. While research on second language acquisition has been under the way for a long time on a large scale. With the development of second language teaching, many researchers and educators try to find out the factors affecting second language Acquisition (SLA). SLA is a complicated and systematic process, which will influenced by many factors that affect and interact each other. This essay will make a further analysis on the social factors and individual factors in the process of SLA, with the expectation that it can bring implications to teachers as well as learners.
\end{abstract}

Index Terms-SLA, factors, implications

\section{INTRODUCTION}

With the rapid pace of globalization, there are more opportunities for cooperation between countries and communication between people all over the world, as a result of which many people, besides students, are eager to master an second language, featuring the learning of English. It's not easy for Chinese to learn a second language and to use it properly, because there are many factors which will affect our second language acquisition. This essay will analyze the political, economic, cultural as well as technological factors and the factors of age, motivation, character as well as attitude, which are divided into two groups respectively--- social factors and individual factors. On when we realize the factors affecting our learning, can we tech and learn more efficiently. Thus it will also offer help to both teachers and learners.

\section{The Definition of SeCond Language Learning}

Second language acquisition can be defined as a kind of language leaning that people learn, besides their mother tongue, inside and outside classrooms. By learning the relative principles of the second language and improving the ability to use it, learners can master the language and can use it properly.

The research on SLA is based on that of mother tongue acquisition. The differences between them lie in the fact that SLA generally goes on out of the environment of the target language and on the premise that learners have mastered their mother tongue. Nowadays, it's a trend to master a second language, which is a proof of one's competence. Therefore, how to learn a second language well and how to make the best use of those factors affecting SLA are really important to learners.

\section{DifFerences BetweEn LANGuage ACQuisition AND LANGUAGe LEARning}

One point we should know better is that "acquisition" differs greatly from "learning". Language acquisition refers to a subconscious process in which people acquire the language through social communication and then use the language properly, which is quite similar to the process they acquire their mother tongue. With the acquisition of the language, people can communicate easily, which is a natural process and features the natural usage without learning studiously.

Language learning is a conscious learning process, usually obtained in a fixed setting, mainly in school settings. In the process of language learning, people focus on the rules of the language and the conscious learning of the systematic knowledge of grammar, vocabulary, and pronunciation, etc, instead of the practical usage. People always can not have a fluent communication with such kind of learning.

To Krashen, learning doesn't equal to acquisition, and it's only function is to monitor and edit the output information of a learner (Krashen, 1982). Obviously, language acquisition is more important than language learning, and the former should be final goal of the latter.

From the theories above, it can be concluded that it will be more efficient for students to acquire rather than learn a second language. The process of SLA is the psychological process in which learners actively participate, and also the

\footnotetext{
* This paper is part of results of Scientific Research Project granted by Jining Medical University (JY2013RW018).
} 
process in which learners store, process, and then use what they learn. However, we have to create a better language environment and language output to realize the process of SLA.

\section{FACTORS AFFECTING LANGUAGE ACQUISITION}

There are many factors which can influence SLA, including internal factors and external factors. Internal factors, known as individual difference factors, are composed of learner's age, attitude, personality, motivation, and first language proficiency, and the like. While external factors, so-called social factors, usually refer to the political, economic, cultural, and technological environment. Let's have a detailed look at these factors.

\section{A. Internal Factors}

\section{Age}

Keller thought the learner's ability of learning language and motivation are two main factors in a successful language acquisition, while the ability of learning language has much to do with the age of a learner. Age factor is an important physiological factor in both first language learning and second language learning, which has attracted much attention of psychologists, linguists, and educators. They have spent lots of time and energy trying to analyze the relationship between age and SLA from different angles. It's generally believed that children have the advantage over adults in SLA, which has still been hotly debated in terms of learning motivation.

Based on many researches, Cazden holds that children, teenagers, and adults will experience the same learning period, during which they have to deal with language data (Cazden, 1988). However, in terms of learning speed and achievement, there are great differences between them. Generally, adults can do better on the initial stage for their better cognitive ability; while children can do better in pronunciation and standard accent, and after a long period of learning they can be more likely to succeed in acquiring second language and communicating with it. Different people hold different opinions, but the importance of age factor in SLA can not be ignored.

2. Attitude

In most theories, attitude is defined as a reaction to one thing or a kind of thing. In SLA, attitude consists of three parts: cognitive part (the belief in something), emotional part (the degree of likes and dislikes of something), and the part of conation( the intention and action to do something). Attitude seems to be the phantom mental state, but in SLA, it is the tendency of learner's cognition, emotion and action in learning target language, so attitude really plays an important part in SLA. In the process of bilingual research, Baker has emphasized the significance of attitude (Baker, 1988). Attitude includes positive one and negative one. With positive attitude, a learner will be active in communicating with the people speaking target language, which will promote the SLA. Holding a negative attitude, a learner tends to refuse or be afraid to contact the people speaking target language, which will definitely hinder the development of SLA and the improvement of the communicative ability.

Of course, attitude is not hereditary, instead, it will affected by the environment, while it is relatively steady. Larsen-Freeman and Long ever mentioned factors affecting attitude: parents, friends, teachers, learning environment, etc.(Larsen and Long, 1991). At present, in China, English is the language, widely taught and learnt. The attitude of Chinese learners exerts a big impact on its learning efficiency. Besides the factors affecting attitude mentioned above, the main factor affecting the attitude of Chinese learners is the learning experience in class. So teachers should improve the teaching and learning efficiency in class by making English class more interesting and attractive.

3. Personality

Personality factors consist of self-esteem, anxiety, depression, spirit of adventure, extraversion and introversion, etc, which will have an effect on SLA and will make much difference to learning efficiency. Psychologically speaking, personality can be divided into extraverted one and introverted one. Compared with an introvert, an extravert is more likely do better in SLA, because extraverted personality endow the learner with optimism, better socializing ability, and strong desire to communicate with others, especially the person speaking target language, which will help create more opportunities to practice the target language for a learner. While the introvert often miss the chances for language learning and practice, because the introverted person tends to be inactive in networking, language learning and communication, which are all obstacles to SLA. The extravert often shows optimism, spirit of adventure, self-confidence, while the introvert is always shy and afraid of making mistakes, and lack self-confidence. It is additionally added that many Chinese learners are introverted ones, who are always too shy to be active in SLA. Only when a person is not afraid to make mistakes and is ready to explore, can he/she achieve what he /she wants in SLA. According to the research by Krashen, it can be concluded that different personalities exerts an impact on whether the learner can speak fluently in oral English in SLA (Krashen, 1981). Everything cuts both ways, so does personality. An extravert in SLA is likely to pay little attention to basic form of language and always lack the endurance in deep thing and research, which an introvert often can do well in. So we can see that these two different personalities have both an active and negative effect on SLA, but in general extraverted personality can do better than the introverted one in SLA.

4. Motivation

Motivation is an internal process that stimulates an individual's activity and helps them to maintain the effort to realize their expected goal (WEI Fang-fang and HE Hua-qing, 2013). As an internal impetus, motivation can promote the learning process, and can inspire and guide learners' learning. There is no doubt that motivation plays an important 
role in a second language learning. To some extent, whether the learner 's motivation is strong or not directly affects the learning efficiency. Learners with definite motivation are always active in participating in foreign language learning, which often results into high learning efficiency. On the contrary, learners with weak motivation always take a negative attitude in the learning process, and they tend to spend less time and energy in a second language learning, which often lead to low learning efficiency.

Motivation has been the focal point of the research of SLA for a long time. Skehan holds that motivation appears to be the second strongest predictor of success, trailing only aptitude(Skehan, 1989).After the research on the relationship between motivation and SLA, Gardner and Lambert propose Gardner and Lambert proposed that there are two main types of second language learning motivation: integrative motivation and instrumental motivation(Gardner and Lambert, 1972).

Integrative motivation features the strong desire of learners to mingle with the people speaking with target language, and the learners' appreciation of a second language and people as well as culture related.

Learners with integrative motivation see SLA as the goal of their interests, which they will be active to achieve. While learners with instrumental motivation regard SLA as a utilitarian goal, which will be achieved by finding a job, passing exams, improving their social status and income, ...everything can help them to be qualified for the future job or life. This kind of motivation is particularly obvious for nursing majors in Medical University, who needn't pursuit a further study and can obtain a job after their graduation as a qualified graduate. So SLA is just a tool for them to gain other benefits. They are inactive in class activities and seldom communicate with their foreign teachers after class. As to integrative motivation, clinical majors are a case in point: most of them will pursuit postgraduate study or study abroad, so they pay little attention to fulfilling one goal, instead, they focus on improving their comprehensive abilities of English. They are always active in class activity and all kind of English activities after class, for example, Oral or writing English contest. And they like to contact their foreign teachers and want to be approved by them. We can see the differences of two types of motivation from the performances of these two majors.

5. First Language Proficiency

First language (L1) refers to a learner's mother tongue. The proficiency of his/her mother tongue will impact greatly the learning efficiency of SLA, because language transfer often happens during the learning process of SLA. Language transfer, first put forward in 1950s, refers to the fact that in the process of a second language or foreign language learning, learners tend to handle the information of target language with the sentence structure and communication strategies of their mother tongue because they don't know or are not familiar with the target language.

In SLA, it can be divided into positive transfer and negative transfer. When mother tongue has a positive effect on a second Language learning because of the similar components between them, positive transfer happens, which can help learners to master and practice a second language. Due to differences between two language, mother tongue often exert a negative impact on SLA, which is called negative transfer that is an obstacle to language learning. Positive transfer and negative transfer often coexist in the process of language learning. Though negative transfer has a negative effect on SLA, it can help us realize the factors hindering language learning, in which negative transfer will change into positive transfer.

Since language transfer is inevitable, we should take the advantage of the positive one to improve learning efficiency of SLA, and try to find out the reasons for negative transfer to turn it into positive one. Then language transfer will be a good way for learners to master a second language.

\section{B. External Factors}

Language drives from social life and social environment, and it develops with the development of our society.

1. Political Factor

With the implementation of the Reform and Opening policy, it's much easier for people to go abroad and to keep up with the latest news abroad, which aroused a strong passion for a second language or foreign language learning among Chinese people. Meanwhile, almost all schools and universities began to reform and innovate curriculums, especially English course. It's reported that Beijing Foreign Study University will add more minority languages to adapt to political development of China. And the upsurge of enthusiasm for English learning has helped non-governmental educational institutions spring up, typically represented by Crazy English Educational School and New Oriental English School. The liberal political policy provides an excellent environment of a second language learning for people.

But, we have to see that among the craze for English, there are unreasonable parts, which is illustrated obviously by the appearance of "aphasia for Chinese culture". Here "aphasia" implies two points: One, when learning English, many Chinese learners don't catch chances to get Chinese culture involved into the learning process, which make the learning divorced from local culture. Two, After learning English, many Chinese learners lose the ability to properly express their Chinese culture in English. The reason for "aphasia" may be that many people are just unreasonably crazy for a second language without the total understanding it and they didn't correctly hand the relationship between their mother tongue and a second language, which definitely exert a negative impact on SLA.

Political situation exerts a subtle influence on SLA. If two countries are hostile to each other, people of these two countries will hold hostility and prejudice to each other, too, which certainly hinder them learning from each other about their culture and language.

2. Economic factor 
A country's economic strength plays a significant role not only in its politics but also in its culture. In the financially underdeveloped countries, people always tend to neglect the importance of their culture, so-called social anomie. It is illustrated by the strong desire of some people to learn about different cultures and different life styles of other countries, which is a driving factor affecting SLA, for example, people who want to immigrate to American will spare no efforts to learn English. Of course, countries with strong economy can spend more on education, A second language learning included.

Individually speaking, to get a job or offer a guarantee of the job is the main motivation to learn or acquire a second language. In China, many people learn English with economical orientation--- mastering English can help them get more opportunities to obtain a job in transnational corporations, where they can be better paid.

3. Technological Factor.

The development of economy will promote that of technology. The writer will set America as an example. As one of economic powerhouses, America advances in science and technology. Computer has been an indispensible practical tool in people's daily life, while over ninety percent of computer language(/program) came from American Microsoft Corporation, which forces many users to learn English in order to better operate computer or enable themselves to handle the problems appearing in the running process.

In 1840s, there was a global craze for learning English. According to a research, most parents in many countries will help their children to choose English as a compulsory course, and many countries asked primary schools to set up English course while more and more overseas students study English abroad. English schools or institutions have sprung up world-widely and offer more positions for people to teach English, which has promoted the upsurge of English learning.

\section{IMPLICATION FOR TEACHING}

At present, SLA happens mostly in classrooms, where teachers pay much attention to vocabulary and grammar while learners seldom have the chances to practice what they learned. After analyzing the factors affecting SLA, we may find out much enlightenment for teaching and learning.

\section{A. Teaching Enlightenment}

\section{To Create Language Environment}

Based on the analysis of the factors affecting SLA, we can conclude that in the teaching process, teachers should focus on students' acquiring instead of learning a second language. The process of SAL is a psychological process in which learners actively participate and what learners learned will be stored, processed and practiced. Only by creating a better language environment and language input, can the process of SLA be realized. Therefore, in order to improve the efficiency of language teaching, teachers should attach importance to creating language environment. First, teachers can introduce more about the culture and custom of the target language to attract learners' interest in SLA; Second, teachers should create a pleasant environment for learners to reduce learners resistance in a second language learning. For example, through multimedia, teachers can make language learning more interesting; Third, teachers should hold or encourage learners to hold more activities related to language learning, which can help learners to practice what they have learned.

2. To provide more comprehensible input

Language learning is mainly achieved by getting a lot of understandable input, which is mainly composed of listening and reading.

According to the comprehensible input hypothesis proposed by Krashen, if we want to make the best use of language input in SLA, we should process the meanings of it and make the materials input interesting and understandable, which can help learners master the language imperceptibly. In classroom, it is teachers who are responsible for providing students with comprehensible input besides the expression of grammar.

3. To Pay Much Attention to the Feedback on Learning

Feedback from teachers on learners' learning is a kind of assessment, which consists of oral compliment and criticism. Through feedback, learners can know exactly the efficiency of their language learning, which can help them to correct the wrong and enhance the right in the future learning. Authentic feedback on learners hard work is of help to improve their language learning, and the sense of achievement is the motivation for the improvement of learners in SLA.

\section{B. Learning Enlightenment}

\section{To Set Up a Specific Goal}

Learners with specific goals are more likely to be better motivated in a second language learning. Because learning motivation is the intrinsic driving force which will directly promote a learner's learning process and efficiency. For example, if the goal of a learner is to study abroad, he or she should learn more about cultures and customs of the country speaking target language, which will also motive him/her to practice oral English more by join activities like Oral English Contest and to be active in communicating with his/her foreign teachers in class. If a learner aims at passing CET4/6, he/she should focus on writing, reading and translating, which accounts for over 60 percent in CET\$/6.

2. To hold a positive attitude 
Since people differs a lot from each other, so-called individual differences, it's natural that the learning efficiencies will be different among different learners. A learner should realize the individual differences and accept them. When a learner doesn't achieve what he or she expected, he/she should find out the reasons and go on with his/her learning step by step instead of being overanxious, depressed or even giving up. Only when learners look at individual differences in a right way and learn according to them, can learners obtain their own achievements in a second language learning. Holding a positive attitude means not only accepting individual differences but also actively handle the problems occurring in the learning process.

3. To Improve First Language Proficiency

As is mentioned in the former part of this essay, first language proficiency what kind of language transfer, positive or negative, happens in SLA. When their first language is poor, their mother tongue will exert an negative effect on their second language learning, which makes them proceed slowly or even fail in SLA. Thus, first language proficiency is the basis of one's SLA, for the reason of which one should learn one's mother tongue better and know better about the differences between first language and target language, which helps positive transfer happens and cushion the negative one. As a result, the achievement in SLA will be remarkable.

4. To Carry Out More reading

Many studies have found that reading can help learners to improve their pragmatic competence and widen their scope of knowledge, which will lay a good foundation for future learning.

Reading can be divided into two kinds: extensive reading and classified reading. Extensive reading refers to reading a large number of materials of target language, including cultural background, short humorous stories, literature works, technological essays, and so on, because it's hard to find the articles without language context. Nowadays online reading are popular and has become important contents of modern consciousness, which can help learners to keep up with the latest news of target language, to update their pragmatic knowledge data, and improve their abilities of practicing a second language. Classified reading means that learners read a certain category of articles with purpose. It can help learners with high levels can summarize what they've learned in the learning process and to some extent offer a rapid way to improve accuracy in language usage.

\section{CONCLUSION}

There are many factors affecting SLA, which are inter-connected, interacting and inter-promoting. Fortunately, in recent years, many educators and linguists, home and abroad, have done many researches and have put forward many constructive suggestions. As a foreign language educator, he or she should know better about the individual differences and teach learners according to their aptitude. Language teachers should facilitate a second language learning with the help of multimedia, internet platform, mobile communication devices, ... everything available. As learners, they'd better put factors affecting SLA, individual and social, in perspective, and take the advantage of them to succeed in Second language acquisition.

\section{REFERENCES}

[1] Baker,C. (1988). Key Issues in Bilingualism and Bilingual Education. Clevedon, Avon: Multilingual Matters.

[2] Courtney, Cazden, (1988). Classroom Discourse: The language of Teaching and Learning. Portsmouth, NH: Heinemann Educational Books.

[3] Gardner, R. C., \& Lambert, W. E. (1972). Attitudes and Motivation in Second Language Learning. Rowley, MA: Newbury House Publishers.

[4] Krashen, S. (1981). Second Language Acquisition and Second Language Learning. Oxford: Pergamon Press.

[5] Krashen .S. D. (1982). Principles and Practice in Second Language Acquisition. New York: Pergamon Press Ltd.

[6] Larsen-Freeman, D. and M. Long. (1991). An Introduction to Second Language Acquisition Research. London: ongman.

[7] Skehan, P. (1989). Individual Differences in Second-Language Learning. London: Edward Arnold.

[8] WEI Fang-fang, and HE Hua-qing. (2013). The Effects of the Motivation Factors on the Second Language Acquisition in Individual Differences. Overseas English (1X), 41-44.

Yuefang Sun, born in Jining, Shandong Province in 1979. She received the bachelor degree from Shandong Science and Technology University in 2002, and the master degree from Qufu Normal University in 2012.

She is currently a lecturer in School of Foreign Languages, Jining Medical University, Jining, China. She has been teaching in Jining Medical University for seventeen years; courses taught include Integrated English, and Traditional Chinese Cultures (English version); Her research interests include Applied Linguistics and second language acquisition. 